\title{
MPLM On-Orbit Interface Dynamic Flexibility Modal Test
}

\author{
Paul S. Bookout \\ Marshall Space Flight Center \\ ED21 Bldg 4610 \\ MSFC, AL 35812 \\ 256-544- 1490
}

\author{
Ian Tinson \& Paolo Fleming \\ Alenia Spazio S.p.A. \\ Strada Antica di Collegno \\ Turin, Italy \\ 39-011-7180-754
}

\section{Introduction}

Now that the Space Station is being constructed, payload developers have to not only verify the Shuttle-to-payload interface, but also the interfaces their payload will have with the Space Station. The Multi Purpose Logistic Module (MPLM) being designed and built by Alenia Spazio in Torino, Italy is one such payload. The MPLM is the primary carrier for the International Station Payload Racks, Re-supply Stowage Racks and the Resupply Stowage Platforms to re-supply the Space Station with food, water, experiments, maintenance equipment and etc. During the development of the MPLM there was no requirement for verification of the on-orbit interfaces with the Space Station. When this oversight was discovered, all the dynamic test stands had already been disassembled. A method was needed that would not require an extensive testing stand and could be completed in a short amount of time. The Residual Flexibility testing technique was chosen.

The residual flexibility modal testing method consists of measuring the free-free natural frequencies and mode shapes along with the interface frequency response functions (FRF's). Analytically, the residual flexibility method has been investigated in detail by, MacNeal (1971) (Reference 1), Martinez, Carne, and Miller (1984) (Reference 2), and Rubin (1975) (Reference 3), but has not been implemented extensively for model correlation due to difficulties in data acquisition. In recent years improvement of data acquisition equipment has made possible the implementation of the residual flexibility method as in Admire, Tinker, and Ivey (1992) (Reference 4), and Klosterman and Lemon (1972) (Reference 5). The residual flexibility modal testing technique is applicable to a structure with distinct points (DOF) of contact with its environment, such as the MPLM-to-Station interface through the Common Berthing Mechanism (CBM). The CBM is bolted to a flange on the forward cone of the MPLM. During the fixed base test (to verify Shuttle interfaces) some data was gathered on the forward cone panels. Even though there was some data on the forward cones, an additional modal test was performed to better characterize its behavior. The CBM mounting flange is the only remaining structure of the MPLM that no test data was available. This paper discusses the implementation of the residual flexibility modal testing technique on the CBM flange and the modal test of the forward cone panels.

\section{Test Description}

The MPLM structural testing article was configured in a free-free test stand, Figure (1), at Alenia Spazio, Torino, Italy, (Reference 6). It was supported by a bungee suspension system to uncouple the hoisting device from the MPLM. The suspension system was 
also instrumented to determine any influence it might have on the dynamic characteristics of the test article. The testing was conducted in two stages. First, a modal test of the CBM and forward cone was performed to determine their primary modes. Second, the drive point Frequency Response Functions (FRFs) were obtained using sine sweeps. This data will be used to determine the dynamic flexibility of the interface.

The excitation positions during the tests, Figure (2), were located on the CBM flange since it was the primary area of interest. However, even though the forward cone panels were excited they were not fully characterized.

\section{Modal Test}

Twenty-four tri-axial accelerometers were used to gather data during the modal test of the forward cone and CBM flange of the MPLM, Figure (3). A 640-channel 'concurrent acquisition system driven by ISTAR software was utilized in acquiring the accelerometer output during the test. The test frequency band was $10-150 \mathrm{~Hz}$ using sine sweep excitation. Four exciter set-up configurations were used in the testing (axial excitation, points $+/-Y$ and then $+/-Z$, radial excitation, points $+/-Y$ and then $+/-Z$ ). Four sinusoidal sweeps up to $150 \mathrm{~Hz}$ (for a total of 16 sweeps):

- with both exciters activated (in phase)

- with both exciters activated (out of phase)

- with one exciter activated

- with the other exciter activated.

One or two $200 \mathrm{~N}$ shakers (depending on test configuration) suspended from small, mobile cranes were utilized to apply the sinusoidal forces to the CBM interface ring. Being controlled by in-line force transducers a force of $20 \mathrm{~N}$ was used to excite the structure.

A total of 74 modes were identified between $25-143 \mathrm{~Hz}$. It was discovered that a large number of forward cone panel modes was present causing a high modal density. The forward cone panels modes stared at $\sim 65 \mathrm{~Hz}$. Each significant mode of the CBM flange was accompanied by various combinations of the cone panel modes. This made it difficult in determining the exact frequency of the CBM flange. For example, the $1^{\text {st }}$ CBM axial mode was excited in the frequency range between $100-108 \mathrm{~Hz}$ depending on the exact arrangement of the exciters. The frequencies of the major CBM modes are listed in Table (1). In addition 6 rigid body modes were also identified, Table (2), three of the bungee system and three of the hoisting device. Careful consideration of the influence of these modes on the test article was taken during the correlation process.

\section{Residual Flexibility Measurements}

Since the MPLM math model had already been correlated to the Shuttle constraints fixed base test, (Reference 7), the global free-free data of the entire MPLM was not obtained. So there for the full potential of the residual flexibility method could not be utilized. However, by obtaining the drive point frequency response functions the dynamic flexibility of the interface could be measured. 
The drive point FRFs, Figures (5) and (6), were taken at $0^{\circ}, 90^{\circ}, 180^{\circ}$, and $270^{\circ}$ around the CBM flange. Abroad-band sine sweep was used to excite the MPLM in the range of $10-150 \mathrm{~Hz}$. The X-direction fundamental anti-resonance is at $14.5 \mathrm{~Hz}$ with the rigid body hoist pitch mode showing up at $26 \mathrm{~Hz}$, Figure (5). The Y-direction fundamental antiresonance is at $33 \mathrm{~Hz}$ with the other two rigid body modes of the hoisting system showing up at $45-50 \mathrm{~Hz}$, Figure (6). It has not been determined why the measurements at location \#7 did not correspond to the expected FRF shape at location \#3. All efforts were taken to determine the phenomenon (accelerometer calibration, attachment, etc.). The mode shapes did not show any peculiarities at location \#7, and the finite element model (FEM) used to for pretest analysis, predicted similar results as point \#3.

\section{Finite Element Model Initial Comparison}

The finite element model used for the pretest analyses had been previously correlated to the test data of the Shuttle's constraints fixed base modal test. The fixed base modal test and correlation was performed in 1996-1997, (Reference 7).

The initial comparison of the modal data, Table (3), of the FEM and the test data indicated good frequency comparison of the primary CBM modes. The Modal Assurance Criteria (MAC) calculations of the mode shapes were poor $(0.34-0.1)$ when using all 24 tri-axial accelerometers (CBM Flange and forward cone). The poor MAC values were due to the extra cone panel modes that accompanied each primary CBM mode. By excluding the cone panel measurements in the MAC calculations of the CBM flange (i.e. 8 tri-axial accels on the CBM flange), the MAC values were considerably better $(0.85-0.56)$.

The drive point FRF comparison of the CBM flange in the X-direction, Figure (7), showed similar characteristics of the curves. The fundamental anti-resonance is well defined but about $20 \%$ too high $(17 \mathrm{~Hz}$ compared to $14.5 \mathrm{~Hz})$. This indicates that the model is too stiff in the axial direction. The Y-direction (radial) FRF comparison, Figure 8 , was not as comparable as the X-direction. The test FRF cure had the fundamental characteristics of a typical drive point FRF, but the anti-resonance was not well defined. The model was considerably worse with no distinguishable anti-resonance. In general the model's FRF seemed to be too stiff also.

\section{Conclusion}

In the initial dynamic testing of the MPLM the on-orbit interface CBM flange was overlooked. A quick and inexpensive test/correlation was needed to verify this interface. The implementation of the residual flexibility testing method was accepted by the International Space Station's Structures Working Group for verification of the MPLM's on-orbit interface. However, due to the previous correlation of the finite element model of the MPLM to the Shuttle's constraints fixed base test, the global free-free measurements were not taken. This limited the implementation of the residual flexibility method. Even though the full potential of the residual flexibility method was not implemented on the verification of the on-orbit interface of the MPLM, enough information was gathered during the testing to correlate the finite element model. A 
following paper will discuss the correlation efforts of the MPLM's on-orbit structural interface (i.e. CBM flange).

\section{References}

1. MacNeal, R. H., 1971, "A Hybrid Method of Component Mode Synthesis," Computers and Structures, Vol. 1, pp. 581-601.

2. Martinez, D. R., Carne, T. G. and Miller, A. K., 1984, ’'Combined Experimental/Analytical Modeling Using Component Mode Synthesis," Proceedings of the 25th Structures, Structural Dynamics and Materials Conference, pp. 140-152.

3. Rubin, S., 1975, "Improved Component Mode Representation for Structural Dynamic Analysis," AlAA Journal, Vol. 13, pp. 995-1006.

4. Admire, J. R., Tinker, M. L., and Ivey, E. W., 1992, "Residual Flexibility Test Method for Verification of Constrained Structural Models," Proceedings of the 33rd Structures, Structural Dynamics and Materials Conference, pp.1614-1622.

5. Klosterman, A. L., and Lemon, J. R., 1972, "Dynamic Design Analysis via the Building Block Approach," Shock and Vibration Bulletin, No. 42, Pt. 1, pp.97-104.

6. Alenia Spazio documnet: MLM-TN-AI-0241, "MPLM Residual Flexibility Test”, Issue 1 Dated 21-Feb-2000

7. Alenia Spazio documnet: MLM-RP-AI-0182, "MPLM Modal Survey Test: Analysis Measured Results Correlation \& Mathematical Model Updating", Issue 1 Dated 14-Feb-1997

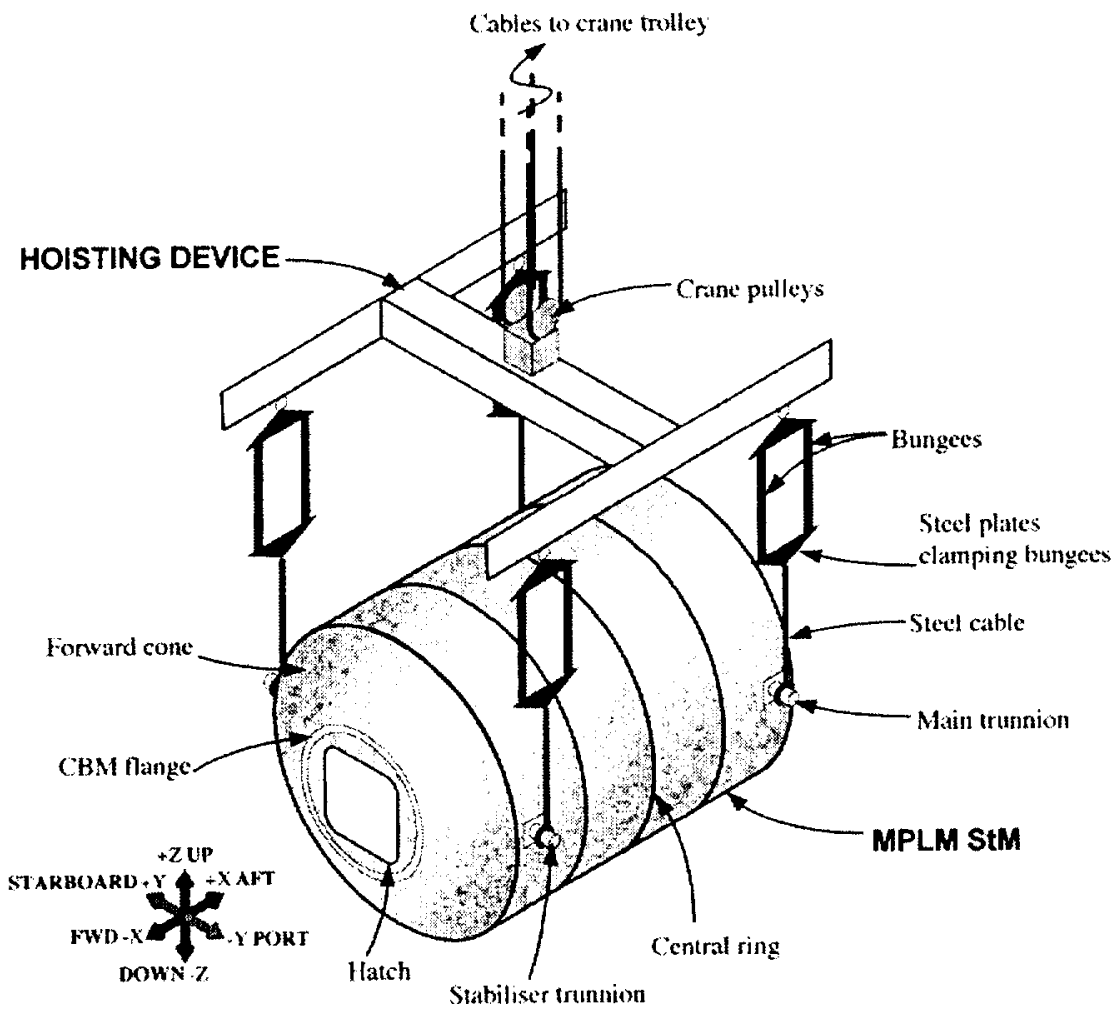

Figure 1, Test Configuration 

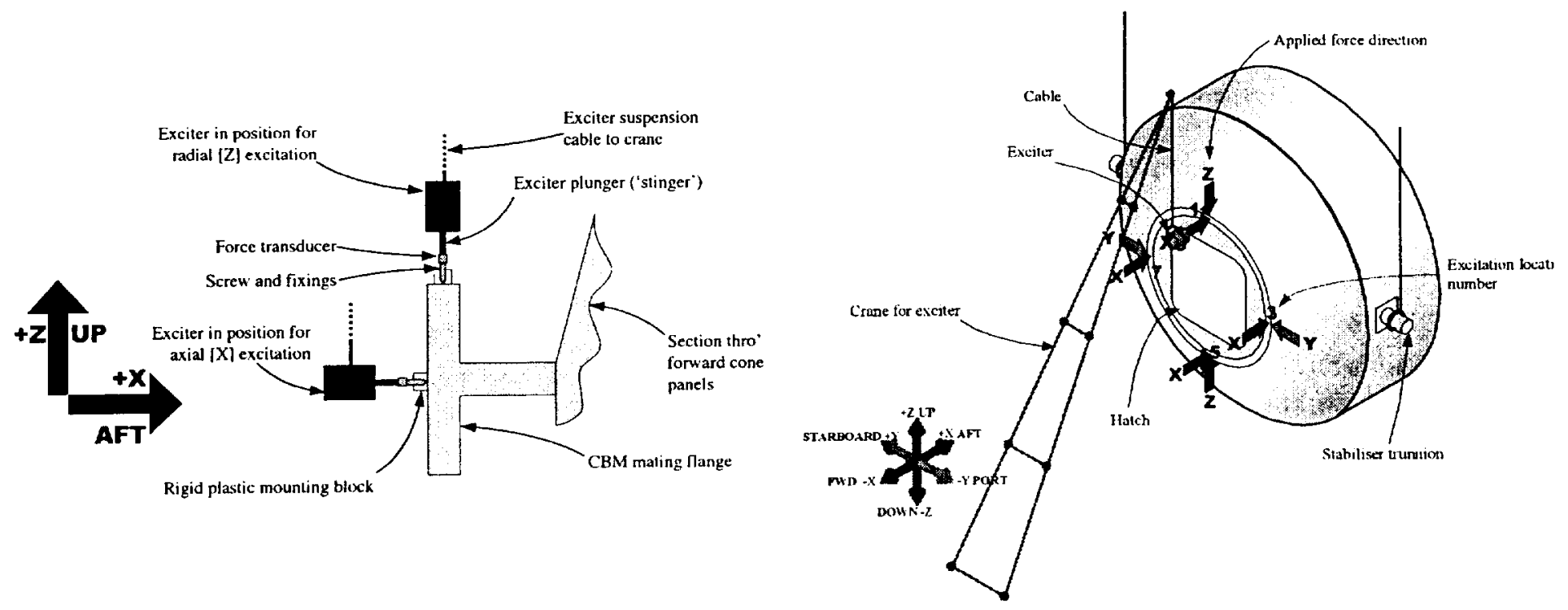

Figure 2, Excitation Location

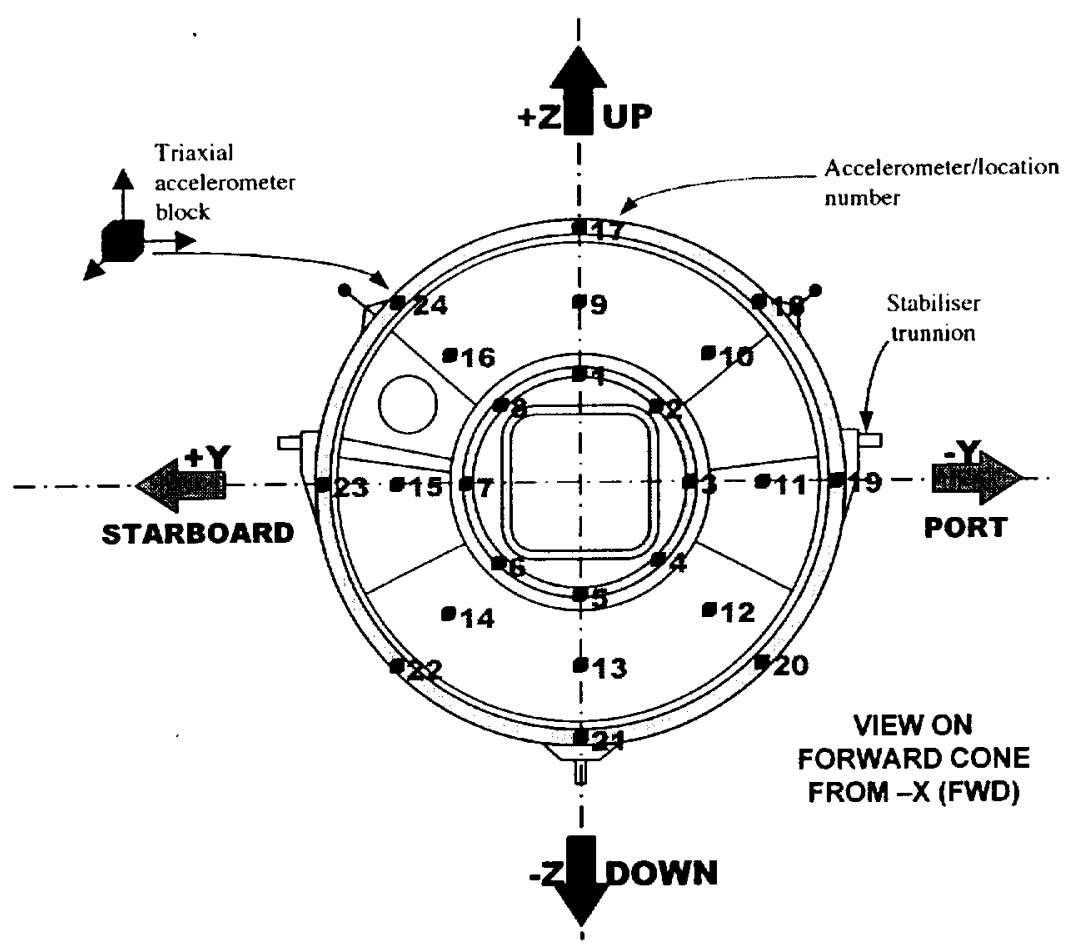

Figure 3, Accelerometer Locations 


\begin{tabular}{|c|c|}
\hline ELASTIC MODE DESCRIPTION & FREQUENCY \\
\hline $1^{\text {st }}$ CBM Axial Mode & $104 \pm 5 \mathrm{~Hz}$ \\
\hline CBM Bending Off-Axis & $>116 \mathrm{~Hz}$ \\
\hline CBM Rotation About $Z_{\text {MPL }}$ & $125 \pm 6 \mathrm{~Hz}$ \\
\hline CBM Rotation About YMPLM & $128 \pm 6 \mathrm{~Hz}$ \\
\hline CBM Bending About YMPL $_{\text {MP }}$ & $130 \pm 6 \mathrm{~Hz}$ \\
\hline CBM Bending About ZMPL & $143 \pm 6 \mathrm{~Hz}$ \\
\hline
\end{tabular}

Table 1, Elastic Mode Frequencies

\begin{tabular}{|c|c|c|}
\hline \multicolumn{2}{|c|}{ RIGID BODY MODE DESCRIPTION } & \multirow{2}{*}{ FREQUENCY } \\
\cline { 1 - 2 } TYPE & SOURCE & \\
\hline $1^{\text {st }} R_{y}$ Mode & Bungees & $0.28 \pm 0.01 \mathrm{~Hz}$ \\
\hline $1^{\text {st }} X / Y$ Mode & Bungees & $0.52 \pm 0.01 \mathrm{~Hz}$ \\
\hline $1^{\text {st }} Z$ Mode & Bungees & $0.84 \pm 0.02 \mathrm{~Hz}$ \\
\hline $2^{\text {nd }} R_{y}$ Mode & Hoisting Device & $26 \pm 1 \mathrm{~Hz}$ \\
\hline $1^{\text {st }} R_{z}$ Mode & Hoisting Device & $48 \pm 1 \mathrm{~Hz}$ \\
\hline $2^{\text {nd }} Z$ Mode & Hoisting Device & $49 \pm 1 \mathrm{~Hz}$ \\
\hline
\end{tabular}

Table 2, Rigid Body Mode Frequencies 


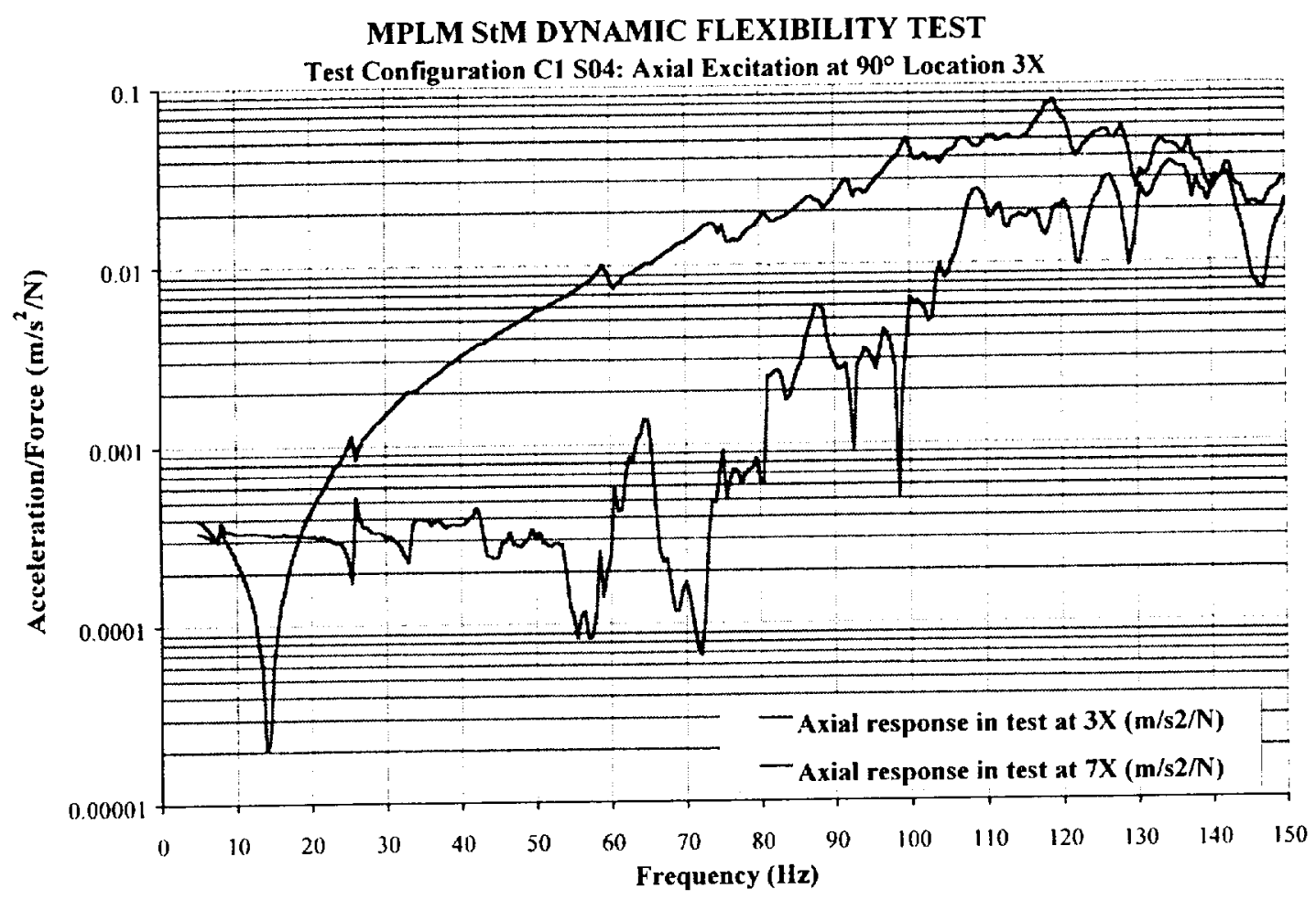

Figure 5, X-Direction Drive Point Frequency Response Function

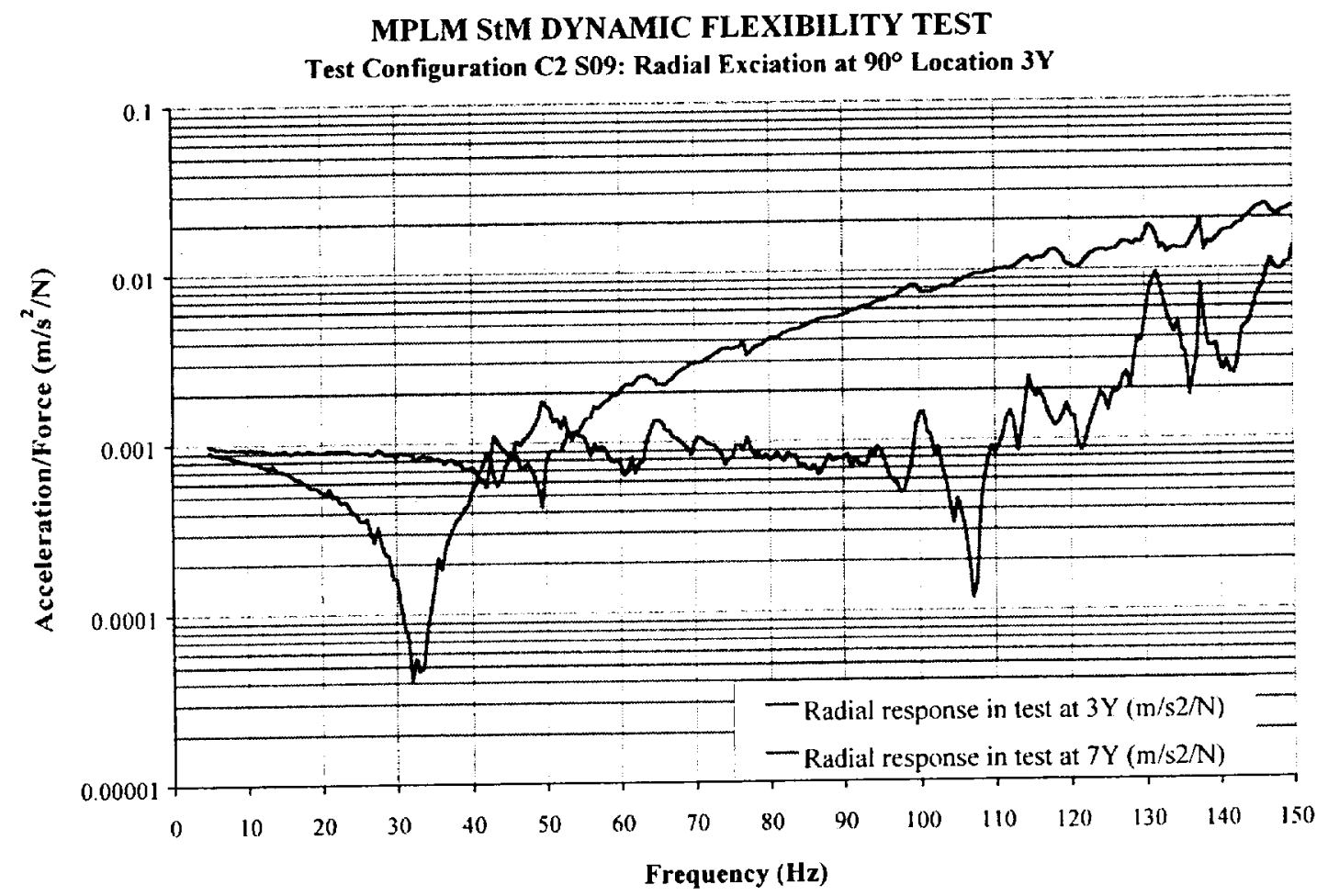

Figure 6, Y-Direction Drive Point Frequency Response Function 


\begin{tabular}{|c|c|c|c|c|c|c|}
\hline \multirow{3}{*}{$\begin{array}{c}\text { Mode } \\
\text { Description }\end{array}$} & \multicolumn{2}{|c|}{ Mode Frequency $(\mathbf{H z})$} & \multicolumn{4}{|c|}{ FEM-Test Comparison } \\
\hline & \multirow[b]{2}{*}{$\begin{array}{c}\text { FEM } \\
\text { Predicted }\end{array}$} & \multirow[b]{2}{*}{$\begin{array}{c}\text { Test } \\
\text { Measured }\end{array}$} & \multicolumn{2}{|c|}{$F_{\text {fem }}-F_{\text {teat }}$} & \multicolumn{2}{|c|}{ MAC } \\
\hline & & & (Hz) & $(\%)$ & $\begin{array}{c}\text { Using } 24 \\
\text { CBM } \\
\text { DOF only }\end{array}$ & $\begin{array}{l}\text { Using all } 72 \\
\text { Test DOF }\end{array}$ \\
\hline Global Pitching Mode & $\begin{array}{c}\text { Not } \\
\text { identified }\end{array}$ & $25.6^{11]}$ & & & & \\
\hline 1st CBM Axial Mode & 105.9 & $107.8^{[1]}$ & -1.9 & $-1.8 \%$ & 0.77 & 0.20 \\
\hline CBM Rotation About $Z$ & 125.0 & $125.2^{\mid 11}$ & -0.2 & $-0.2 \%$ & 0.85 & 0.10 \\
\hline CBM Rotation About $Y$ & 129.7 & $128.2^{[3]}$ & 1.5 & $1.2 \%$ & 0.82 & $<0.10$ \\
\hline CBM Bending About $Y$ & 143.9 & $130.8^{[2]}$ & 13.1 & $10.0 \%$ & 0.56 & 0.34 \\
\hline CBM Bending About $Z$ & 143.9 & $142.7^{[1]}$ & 1.3 & $0.9 \%$ & 0.80 & $<0.10$ \\
\hline
\end{tabular}

Key to table:

[1] Results for test configuration exciters at $90^{\circ} / 3 \mathrm{X} \& 270^{\circ} / 7 \mathrm{X}$

2) Results for test configuration exciters at $0 \% 1 \mathrm{X} \& 180 \%$ XX

[3] Results for test configuration exciters at $0^{\circ} / 1 \mathrm{Z} \& 180^{\circ} / 5 \mathrm{Z}$

Table 3, Initial FEM and Test Data Comparison

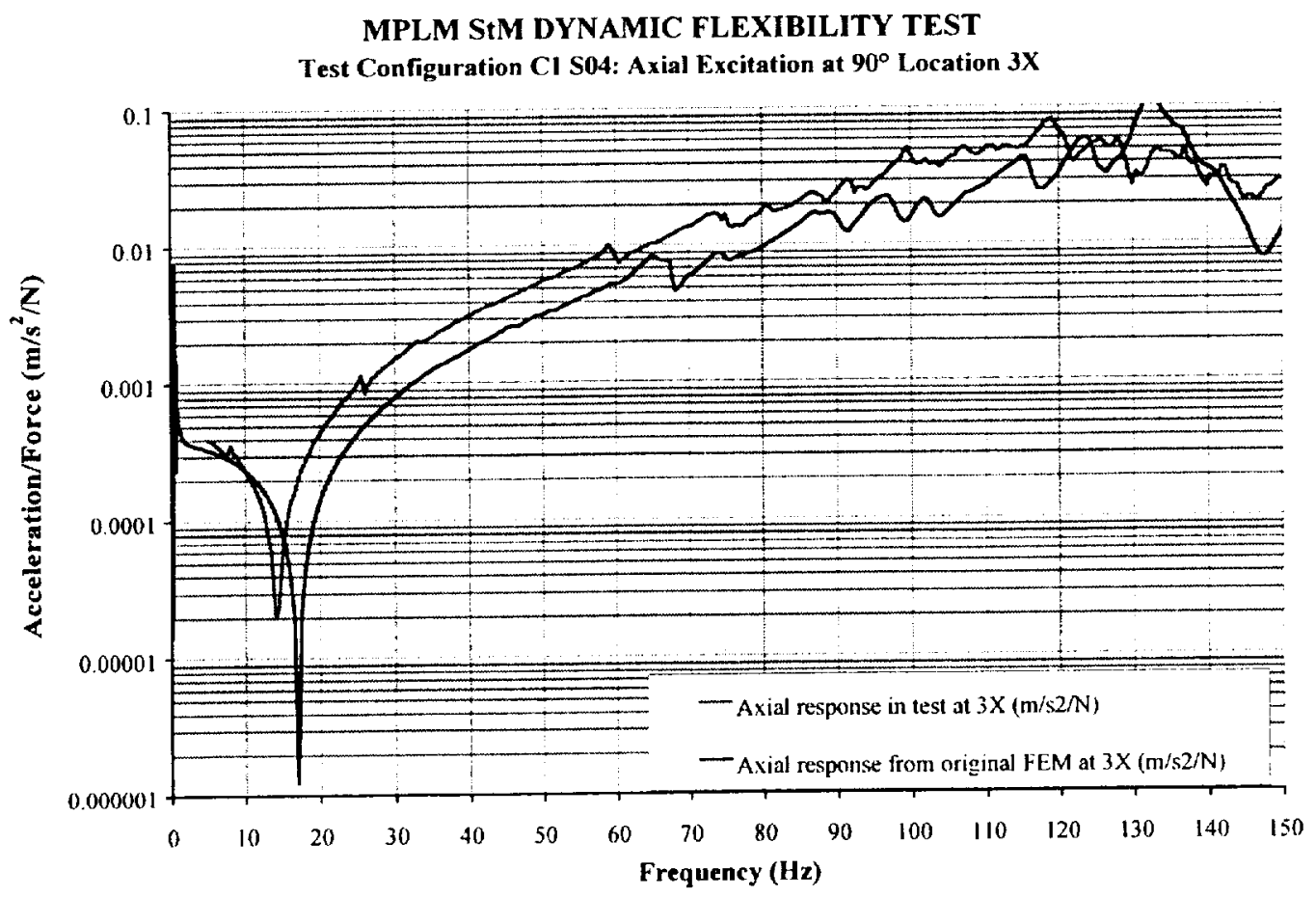

Figure 7, X-Direction FRF Original Comparison 
MPLM STM DYNAMIC FLEXIBILITY TEST

Test Configuration C2 S09: Radial Excitation at $90^{\circ}$ Location $3 Y$

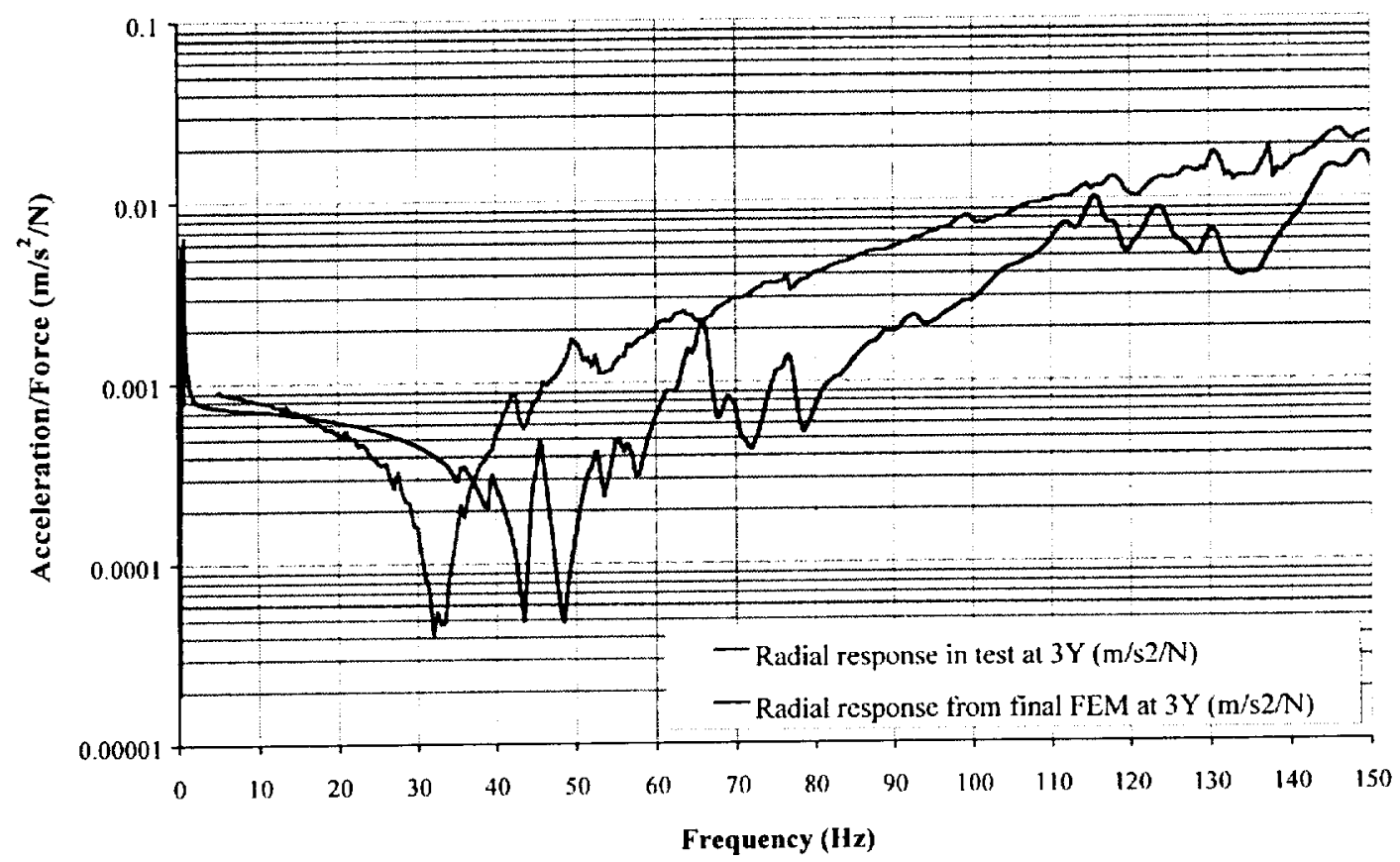

Figure 8, X-Direction FRF Original Comparison 